\title{
DOS REFLEXOS DA CRISE DO DIREITO LIBERAL DA ATUALIDADE QUANDO DO EXERCÍCIO DA PARENTALIDADE RESPONSÁVEL
}

\section{THE LIBERAL LAW CRISIS' REFLEXIONS ON THE CONTEMPORARY EXERCISE OF RESPONSIBLE PARENTING}

\author{
${ }^{1}$ Valéria Silva Galdino Cardin \\ ${ }^{2}$ Marcela Gorete Rosa Guerra Gurginski
}

\section{RESUMO}

A crise social e jurídica da atualidade, oriunda da cultura consumerista, decorre do modelo econômico capitalista e liberal. Devido ao culto dos valores materiais, o ser humano afastouse de sua identidade universal, transformando-se em um ser individualista e egoísta. Evidencia-se que muitas relações familiares são constituídas sem que exista afeto ou dever de cuidado, implicando em desrespeito aos princípios da parentalidade responsável, da dignidade da pessoa humana e do melhor interesse da criança. Assim, faz-se necessário verificar as consequências jurídicas destas relações e propor um retorno ao verdadeiro significado do ser humano e da sua finalidade.

Palavras-chave: Capitalismo, Individualismo, Família, Exercício da parentalidade responsável

\begin{abstract}
The social and legal crisis, coming from the consumerist culture, stems from the capitalist and liberal economic model. As a result of the cult of material values, the human being moved away from its universal identity, becoming a being individualistic and selfish. Many family relationships are constructed without affection or duty of care, implying in disrespect to the principles of responsible parenthood, dignity of the human person and child's best interest . It's necessary to verify the legal consequences of these relationships and propose a return to the true meaning of the human being and purpose.
\end{abstract}

Keywords: Capitalism, Individualism, Family, Responsible parenting

\footnotetext{
${ }^{1}$ Pós-Doutora pela Universidade de Lisboa, UL, Lisboa, (Portugal). Professora do Centro Universitário de Maringá - CESUMAR, Paraná, PR. (Brasil). E-mail: valeria@galdino.adv.br.

${ }^{2}$ Mestra em Ciências Jurídicas pelo Centro de Ensino Superior de Maringá - CESUMAR, Paraná, PR, (Brasil) Auxiliar de Justiça no Juizado Especial da Comarca de Campo Mourão/PR, Paraná, PR.(Brasil). E-mail: marcela.rmg@hotmail.com.
} 


\section{INTRODUÇÃO}

O modelo econômico capitalista deu origem à sociedade de consumo, onde as pessoas buscam a felicidade por meio do culto aos valores materiais e não mais aos do espírito.

Atualmente, verifica-se uma intensa preocupação com a liberdade no sentido negativo, valorizando o ser humano em sua individualidade, a partir de uma concepção nominalista, perdendo, assim, a noção de identidade universal entre as pessoas.

O ser humano moderno se tornou egoísta, calculista e desapegado dos valores éticos ou morais, uma vez que tais concepções foram relativizadas pela subjetividade.

Vive-se uma verdadeira crise social e jurídica que afetam várias instituições da sociedade, principalmente a família.

É certo que, neste cenário de individualidade, o ser humano acaba se relacionando com o outro sem o comprometimento do cuidado. Assim, exerce a sua sexualidade ou o direito ao planejamento familiar, desapegado do dever de cuidado, do dever de exercer a parentalidade responsável, de preservar a dignidade do outro e do melhor interesse da criança e do adolescente, colocando em risco os direitos de personalidade destes, que são os seres vulneráveis destas relações.

O objetivo deste trabalho é, portanto, propor uma análise das causas da crise da atualidade e os seus reflexos nas relações familiares, buscando possíveis soluções para a ausência de solidariedade e de cuidado nos vínculos paterno-materno-filiais.

Neste trabalho científico, foi utilizado o método teórico consistente na pesquisa de obras e artigos periódicos especializados que tratam especificamente da crise da pósmodernidade, da sociedade, do capitalismo, como também dos aspectos filosóficos do ser humano na atualidade e da necessidade de se voltar à metafísica.

\section{DA VALORIZAÇÃO DO CAPITAL EM DETRIMENTO DA NATUREZA HUMANA E OS REFLEXOS NAS RELAÇÕES FAMILIARES}

A partir do liberalismo e da globalização, o mundo tornou-se uma verdadeira "aldeia global” (CARLIN, 1998, p. 34). A corrida imperialista por novos mercados consumidores e a busca desmedida pelo poder econômico, sob os ideais da fraternidade, da igualdade e da liberdade, criaram uma sociedade de hiperconsumo, com a mercantilização das necessidades humanas e dos modelos de vida (LIPOVETSKY. 2007. p. 24-25), atribuindo aos objetos 
verdadeiras paixões consumistas, sendo vivenciada, portanto, a era do hipermaterialismo. Logo, a contemporaneidade passou a ser o palco de uma crise social e jurídica.

Tudo na sociedade de consumo adquire um preço, tornando-se alvo de desejo e, mediante um pagamento, pode ser adquirido por qualquer indivíduo. Trata-se de um ciclo de "sedução" do capital, pois a cada dia um novo objeto é criado para satisfazer as urgências lucrativas do mercado e para manter a rotatividade. Enquanto isso, a pessoa sem identidade ou diferencial qualitativo (MOTTA. 2012, p. 223) acaba transferindo a sua felicidade, bem como a sua realização pessoal na necessidade de adquirir um objeto comercializado.

O indivíduo se tornou refém da ambição material desmedida. A identidade universal voltada para os valores ínsitos à natureza humana deu lugar a uma identidade cultural do objeto, ou seja, as pessoas se identificam a um determinado grupo por meio da aquisição de determinadas mercadorias.

Segundo Zygmunt Bauman a vida passa a ter como fim o consumo, que acaba transformando as próprias pessoas em mercadorias (MOTTA. 2012, p. 13).

O indivíduo ingressou em um processo de decomposição do espírito e da alma, tornando-se escravo de suas próprias invenções (MARX; ENGELS; 2005. p. 11). O valor do capital e da mercadoria esgotou a natureza humana. E o consumismo e o individualismo exacerbado transferiram a concretização da felicidade para a aquisição de bens, e não mais no culto aos valores do espírito e da auto-realização humana (ZENNI, 2006, p. 24-25).

A sociedade capitalista elege o desejo de possuir bens acima de valores como a moral e a ética, fazendo com que as pessoas queiram satisfazer suas vontades consumeristas a qualquer preço. Há um distanciamento do ser do campo ético, do "dever ser”, uma desconexão com a figura do Imago Dei, tornando a humanidade completamente vazia, apática e vinculada a prazeres instantâneos.

Por consequência, há o abandono da ideia de valorização do semelhante enquanto pessoa, para valorar o outro na exteriorização de riquezas (CARLIN, 1998. p. 64).

Neste contexto, Alessandro Severino Vallér Zenni afirma que a crise do direito liberal também traz reflexos em várias instituições da sociedade, principalmente na família. $O$ supracitado autor apresenta cinco causas da crise social e jurídica (CARLIN, 1998. p. 29-51).

A primeira causa seria a liberdade individualista ética e política ou moralismo subjetivista, em que as pessoas são excessivamente individualistas, inexistindo a essência comum. O que torna as pessoas semelhantes é o dom da liberdade e a vontade desmedida de 
exercê-la, baseada apenas em sua própria consciência, muitas vezes com o amparo legal, justificando tais relações em um contrato.

Há uma demasiada preocupação com a liberdade no sentido negativo, que desencadeia a ideia de Estado liberal, neutro, diante das liberdades entre os cidadãos em suas relações, sem impedimentos, "olvidando o sentido positivo de auto realização humana" (ZENNI, 2006. p. $34)$.

Já a segunda causa se apresenta no antropocentrismo humanista em que há uma valorização do homem individualmente considerado, como princípio e fim de tudo, e uma consequente subjetivação das crenças e dos valores, afastando ainda mais o homem de sua essência comum e universal.

Enquanto a terceira causa aparece no individualismo econômico ou no capitalismo liberal em que o liberalismo econômico, sem preocupação com a distribuição da riqueza ou a intervenção estatal na economia, transforma a sociedade hipermaterialista, enaltecendo o "ter" ao invés do "ser", acarretando a desigualdade social.

O individualismo político ou contratualismo é apontado como a quarta causa, e por conta do racionalismo, que assegura o homem a construção de sua liberdade pela razão, há um rompimento entre o direito e o divino, sendo o contrato o único caminho da convivência humana pacífica e segura. Assim, a metafísica deixa de ser um dos ingredientes das ações humanas e da própria norma.

Neste sentido, explica o supracitado autor:

O homem malgrado ser herdeiro de um passado construído com genialidade e esforços põe-se, agora, como um ser mimado pelo mundo à sua volta, sem encontrar limites aos desejos, tendo a impressão de que tudo lhe seja permitido e a nada seja obrigado, perdendo a noção completa de limites e nos eventuais conflitos com outros seres percebe-se a si como único e exclusivo, individualista, detentor de direitos absolutos, sem noção de hierarquia ou superioridade. (ZENNI, 2006. p. 47)

Pode-se, ainda, apontar como a última causa o atomismo massificante, em que os indivíduos estão completamente massificados, sem a essência universal e a natureza comum, mergulhados numa profunda depressão por desconhecerem a realidade de sua estrutura ontológica e axiológica.

Depreende-se, a partir disto, que a modernidade criou um ser nihilista, que perdeu o sentido de sua própria existência, e está tomado por um sentimento de impotência, angústia e solidão, que procura apenas desfrutar de um prazer momentâneo, ocasionado pelo culto dos bens externos (ZENNI, 2006. p. 48). 
Ressalta-se que o consumo desenfreado não edifica nenhuma sociedade, ao contrário, atinge de forma negativa a natureza ontológica da coesão e da perfeição ao bem que deve permear nos agrupamentos sociais, afetando, assim, o indivíduo no convívio com os outros, principalmente no âmbito das relações familiares.

O consumo excessivo faz com que as pessoas demonstrem o afeto por meio dos bens materiais, sem promover um espaço familiar em que os entes possam demonstrar suas ideias, seus valores, e cultivar a convivência familiar saudável.

Destaca-se ainda que o culto a mercadoria é falível, tendo em vista que quando o objeto não corresponde às expectativas, o indivíduo é tomado por uma inquietude e uma angústia, em que o vazio permeia seu foro íntimo, que só será preenchido por outro objeto material, criandose, assim, a política do descarte. A pessoa é acostumada a enfrentar a sua insatisfação descartando as coisas que a causam (ZENNI, 2006. p. 31).

Infere-se um nítido distanciamento do ser humano da política, de sua autorealização, e do próprio convívio humano pacífico, amigável e solidário.

Neste sentido, hodiernamente, as relações familiares são muitas vezes formadas sem se atentar ao real sentido da afetividade, da própria solidariedade familiar, da parentalidade responsável e da dignidade da pessoa humana.

Muitas relações paterno-materno-filiais surgem decorrentes do exercício irresponsável da sexualidade, sem comprometimento com a afetividade, com o cuidado e com a solidariedade, chamadas relações puras (ZENNI, 2006. p. 31-32). por Zygmunt Bauman, ou da própria falta de planejamento familiar dos indivíduos.

A grande questão se revela diante da falta de responsabilidade subsequente dos pais com este novo ser, dependente e vulnerável, que, muitas vezes, desrespeitam os direitos da personalidade das crianças e dos adolescentes, tratando-os como meras "mercadorias descartáveis", uma vez que não lhes trazem a satisfação esperada ou não preenchem o seu ego.

São muitos os casos, até notificados, em que os entes familiares não se comprometem com o outro, e não exercem o devido dever de cuidado com aqueles.

O objeto deste trabalho científico é analisar os efeitos desta crise no âmbito familiar, e quais as possíveis consequências jurídicas frente à parentalidade irresponsável, ao melhor interesse da criança e do adolescente, e aos direitos da personalidade destes.

\section{DOS EFEITOS DA CRISE DA ATUALIDADE EM FACE DA PARENTALIDADE RESPONSÁVEL}


A atual Constituição Federal, com o princípio da dignidade da pessoa humana como epicentro normativo e axiológico do ordenamento jurídico, alterou a estrutura familiar (MADALENO, 2007. p. 116), elegendo como elemento formador da família os vínculos do afeto, adotando uma nova perspectiva de coesão do grupo e de bem-estar de todos, com base no exercício do poder familiar por ambos os cônjuges em igualdade de condições, e o respeito à formação e ao desenvolvimento da personalidade dos entes familiares, principalmente, dos mais vulneráveis.

A partir do princípio da afetividade, "as famílias passam a ter como essência e razão de sua existência a sua comunhão espiritual" (MADALENO, 2007. p. 116). A entidade familiar é o meio para a realização existencial de seus membros, bem como para o pleno desenvolvimento de cada ser como pessoa humana (GIRARDI, 2005. p. 43).

De acordo com Rolf Madaleno (2011. p. 95) "o afeto é a mola propulsora dos laços familiares e das relações interpessoais movidas pelo sentimento e pelo amor", que confere o sentido e a dignidade à existência humana. Traduz-se, portanto, na consideração, no respeito e no dever de cuidado entre as pessoas que compõe o grupo familiar, representando o componente axiológico que fortalece e estrutura a união da família (REIS; PINTO, 2012. p. 505).

Em relação aos pais, a afetividade, ao lado do princípio da parentalidade responsável, fundamento do direito ao planejamento familiar, representará o dever de criar e educar os filhos sem lhes omitir a atenção necessária para a formação plena de sua personalidade, como atribuição do exercício do poder familiar (DIAS, 2007. p. 407).

Embora o casal tenha o direito ao livre planejamento familiar, ou ao livre exercício da sexualidade, a partir do momento em que de tais atos provenha um novo ser humano, caberá aos responsáveis agir com o devido dever de cuidado em relação à criança, desde a sua concepção, ou seja, caberá aos pais a obrigação de prover a assistência moral, material, afetiva, intelectual e espiritual aos filhos (ROSA; CARDIN, 2012).

Nesse sentido Benjamin Moraes (1980, p. 29) afirma que:

Ao estabelecer como dever de ambos os cônjuges sustentar, guardar e educar os filhos, é claro que o legislador brasileiro aí estatui um princípio inequívoco de planejamento familiar: não devem os pais ter filhos sem quaisquer limitações, mas tê-los tantos quantos possam sustentar, guardar e educar. Estas três obrigações legais só poderão ser cumpridas se os cônjuges tiverem em conta os recursos de que necessitam para a sua nobre missão.

“Aqueles que não querem se comprometer com o mínimo de assistência afetiva, moral, intelectual e material que não tenham filhos" ( CARDIN, 2012. p. 239), afinal, ninguém está 
brigado a ter um filho, mas que após o nascimento, precisará de todo um amparo familiar para sua própria subsistência e desenvolvimento biopsicossocial, por ser vulnerável.

Evidencia-se no ordenamento jurídico pátrio todo um aparato de normas com o objetivo de zelar e proteger a criança que está por vir, colocando-a sob especial proteção do Estado, da sociedade e principalmente da família, onde irá desenvolver-se ${ }^{1}$. Entretanto, este insigne conjunto de normas está longe de ser efetivamente concretizado nas relações familiares. Falta o compromentimento do homem com o seu próximo, e consciência da sua própria essência.

A sociedade do capital também afetou os homens em suas relações pessoais, principalmente familiares. A individualidade exarcebada; o subjetivismo dos valores morais e éticos; a valorização de um ser autônomo e auto suficiente sem um fim e detrminado a consumir - que sequer compreende o motivo de sua existência - constrói relacionamentos vazios, sem afetividade e desapegados da ideia de solidariedade ou de compromisso com o próximo.

Por conta disto, quando algo não sai como o esperado, e do exercício da sexualidade resulta o nascimento de um novo ser humano, da mesma forma com que agem diante da insatisfação do consumo, descartam as pessoas, em busca de algo que lhe proporcione "felicidade" ou prazer.

O ser humano, egoísta, crê em direitos absolutos e não reconhece suas responsabilidades, e assim, não exercem o devido dever de cuidado em relação ao menor, frágil, carente do devido amparo material e muitas vezes do amparo intelectual para o desenvolvimento pleno de sua personalidade.

O culto ao capital reveste nas pessoas o desejo pela ostentação e pela riqueza, que tendem a se atrair umas pelas outras por valores materiais, e muitas vezes, usam de subterfúgios para estabelecer um vínculo filial com uma pessoa em razão do seu dinheiro.

Os ideais pútridos do capitalismo sobressaem aos valores do bem comum familiar, colocando os direitos de personalidade das crianças, os seres completamente vulneráveis nestas relações, em risco.

Verificam-se também casos em que, após o rompimento de relacionamentos mal resolvidos, por conta justamente da falta de essência humana e de respeito ao próximo, muitos dos ex-cônjuges usam dos filhos para praticar violência um contra o outro, como por exemplo, a prática de alienação parental.

A criança acometida da síndrome de alienação parental (SAP) sofre tortura mental ou física pelo alienador que lhe instiga sentimentos de ódio e repúdio ao alienado (LAGRASTA NETO; TARTUCE; SIMÃO. 2012. p. 192-193). 
Caetano Lagrasta Neto (2012. p. 192) explana que as crianças que são submetidas à SAP estão sujeitas a graves consequências no futuro, uma vez que se mostram propensas a atitudes antissociais, podendo tornarem-se violentas e criminosas; sofrer de depressão, chegando a cometer suicídio; ou alcançada a maturidade, padecer de forma crônica de desvio comportamental ou moléstia mental pelo sentimento de remorso por ter alienado ou desprezado um genitor ou parente.

Depreende-se, a partir disso, que os filhos passam a ser objeto de realização de desejo pessoal dos seus genitores, um instrumento de vingança.

“A pessoa humana, qualquer que seja o modo pelo qual foi concebida, não pode ser considerada um meio para a satisfação de um fim" (AGUIAR, 2005. p. 90), isto é, todo indivíduo deve ser considerado um fim em si mesmo, e não um meio de satisfação pessoal de outrem.

Acrescente-se ainda, as controvérsias advindas das técnicas de reprodução humana assistida. Com efeito, referidas técnicas permitem ao casal a realização do planejamento familiar de modo artificial, seja por técnicas de inseminação artificial ou fertilização in vitro (CARDIN, 2009. p. 8).

Contudo, alguns destes procedimentos podem acarretar a prática de eugenia.

Hodiernamente é permitido ao casal, que opta pelas técnicas de reprodução humana assistida, a realização do diagnóstico genético pré-implantacional. Trata-se de um exame de alta tecnologia que irá analisar a viabilidade do embrião, ou seja, verificar se determinado embrião pré-concebido está livre de alguma condição genética e plenamente saudável (CARDIN, 2012)

No Brasil, apenas a Resolução do Conselho Federal de Medicina n. 2121/2015 trata do assunto, autorizando a realização do referido exame apenas para avaliar a viabilidade dos embriões in vitro, detectando doenças hereditárias e impedir a transmissão das mesmas ${ }^{2}$.

Todavia, o limite entre a terapia genética para selecionar embriões que não apresente doenças e entre a prática de eugenia, que se refere à escolha de características desejadas, é tenro (CARDIN, 2012), e está fora do alcance do direito e da fiscalização estatal.

${ }^{1}$ Art. 227, caput, da Constituição Federal/88. 
A possibilidade de manipulação genética dos embriões para fins de eugenia coloca em conflito os valores da própria essência humana com os da vida apática do consumo.

Neste sentido, é o entendimento de Jürgen Habermas:

genética desejável dos seus descendentes como um produto que pode ser moldado e, para tanto, elaborarem um design que lhes pareça apropriado, eles estarão exercendo sobre seus produtos geneticamente manipulados uma espécie de disposição que interfere nos fundamentos somáticos da auto compreensão espontânea e da liberdade ética de uma outra pessoa e que, conforme pareceu até agora, só poderia ser exercida sobre objetos, e não sobre pessoas. (HABERMAS, 2010, p. 19.)

Há uma evidente confusão do limite entre as pessoas e as coisas. A possibilidade de escolha das características do embrião resulta numa verdadeira coisificação da própria vida humana, consistindo a criança num verdadeiro produto escolhido e desejável pelos seus pais.

A partir do momento em que existir a possibilidade de escolha de genes e "qualidades" do embrião, impostas pela sociedade de consumo, e este, por sua vez, não atingir a "satisfação pessoal" daqueles que o idealizou, resultará numa nova angústia e inquietude, ensejando na possibilidade de abandono e de desistência do projeto parental, conforme o recente caso que ocorreu nos Estados Unidos, em que os pais biológicos que firmaram um contrato de gestação com uma mãe substituta, ao descobrir que o bebê apresentava anomalias de formação, não quiseram mais dar continuidade ao projeto parental, chegando, inclusive a oferecer uma recompensa para a gestante abortar a criança ${ }^{3}$.

Com efeito, um dia quando os adultos passarem a considerar a composição

Além disso, a eugenia pode trazer em si, camuflada, o racismo, ou para usar da seleção

por um simples capricho (FÉO, 2005. p. 256). Partindo-se de uma análise axiológica, verifica- se que os direitos de ser e estar em igualdade de condições sociais, jurídicas e éticas, pressupõe a ressalva da diferença, isto é, "dignidade e igualdade pressupõe diversidade que não se instala artificialmente" (FACHIN, 2004, p. 180), é elegida por respeito e limites.

Dos casos explanados, todos decorrem da falta de preocupação da essência humana, da perda do culto de valores de espírito, e da auto-realização. O individualismo exacerbado e a cultura consumerista chegam a patamares que colocam em risco direitos da personalidade de

${ }^{2}$ Resolução 2.013/2013 do Conselho Federal de Medicina. Disponível em: http://portal.cfm.org.br/images PDF/resoluocfm\%202013.2013.pdf. Acesso em: 06 set. 2013. 3 SURROGATE ofered $\$ 10,000$ to abort baby. Disponível em: <http://edition.cnn.com/2013/03/04/health/surrogacy-kelley-legal-battle> Acesso: 04 set. 2013. 
pessoas totalmente vulneráveis, e que, sem o devido amparo, não conseguirão desenvolver plenamente a sua personalidade, fato que ensejará um mal para a própria sociedade do futuro, que terão pessoas ainda mais individualistas, acentuando-se as causas da crise da pós-modernidade.

\section{DA FALTA DE AFETO NAS RELAÇÕES FAMILIARES, DAS CONSEQUENCIAS JURÍDICAS E O RETORNO À IMAGO DEI}

A crescente ausência de afeto nas relações familiares demonstra que o homem perdeu o comprometimento com a realização pessoal de cada membro familiar, com os valores espirituais, com a própria dignidade da pessoa humana, e com o melhor interesse da criança e do adolescente.

A incapacidade de assumir as responsabilidades perante a paternidade e a maternidade, resultam danos para o menor, vulnerável, que precisa de total apoio para poder desenvolver-se de forma plena e saudável.

O exercício irresponsável da parentalidade, a falta de dever de cuidado, em todos os sentidos supramencionados, acarreta algumas consequências jurídicas.

Diante de todo o cenário atual da crise social e jurídica, o direito, longe de consagrar a auto-realização humana (ZENNI, 2006. p. 51), no máximo, estabelece sanções e punições aos que praticam ato ilícito.

O poder judiciário, por sua vez, impõe a responsabilidade aplicando sanções punitivas como a prisão, nos casos dos devedores de prestação alimentícia ${ }^{4}$, como também a indenização pecuniária, no caso de abandono afetivo, tendo em vista a prática do ato ilícito que lesa os direitos de personalidade do menor (DIAS, 2007. p. 407).

Por outro lado, a indenização pecuniária não deixa de ter, em sua essência, traços de ordem capitalista, no sentido de que com a condenação, a pessoa aufere um valor para compensar ou amenizar um mal sofrido, fato este que aumenta demasiadamente a demanda judiciária sem, realmente, solucionar o problema.

\footnotetext{
${ }^{4}$ Art. 732 e seguintes do Código de Processo Civil.
} 
Embora o entendimento de que a obrigação de indenizar imposta aos pais que causem um dano para o filho se presta para gerar um comprometimento familiar com o pleno desenvolvimento deste (DIAS, 2007. p. 408), ou para propiciar que a pessoa receba auxílio psicológico para tratar as sequelas resultantes das práticas irresponsáveis (CARDIN, 2012. p. 239), por si só, não faz com que o homem retome aos valores da metafísica, adquirindo consciência de si e da existência do próximo.

É claro que o poder judiciário não pode deixar de tutelar os direitos dos detentores de uma pretensão, ou deixar passar em branco os casos de irresponsabilidade parental. Mas também não se pode acreditar que somente com as indenizações os problemas familiares estarão solucionados.

A atual matriz do pensamento moderno liberal do individualismo, no sentido de é papel do direito garantir a todos segurança da sociedade ao longo do tempo e de estar assegurado a sua identidade, e possibilitar o exercício de sua liberdade individual, sob a premissa de que "não há sujeito livre senão submetido a uma lei que o fundamente" (MOTTA, 2012, p. 224), está fundamentada no nominalismo, concepção esta de que o ser humano não passa de uma existência mental, racional, afastando de forma radical uma natureza comum e universal aos seres humanos (ZENNI, 2006, p. 48).

O homem, neste cenário de individualidade e de consumismo, está destinado a constituir-se por si só, libertando-se de quaisquer limites que definam a condição humana (MOTTA, 2012, p. 224).

A constituição normativa de ser humano na modernidade o fundamenta apenas na razão e em sua própria liberdade, afastando-o da metafísica e perdendo o sentido, a sua própria essência humana. Por conta disto, para uma mudança no atual cenário de crise, seria necessário retomar as razões de existência fora do próprio ser.

Neste sentido, Alain Supiot (2007) propõe um retorno ao significado do ser humano: imago Dei.

O homem está no mundo por seus sentidos, sua existência se desenrola num universo biológico, como também simbólico, daquilo que o espírito humano carregou sentido. Para estar no mundo é preciso que o homem abdique a pretensão de ditar o próprio universo, reconhecendo que este sentido vai além do seu entendimento e da sua razão, afinal, por mais que a racionalidade signifique sempre uma conquista, o universo mental, simbólico, é infinito e não pode ser reduzido pela existência física e científica.

Assim, a concepção teológica do imago Dei, do homem concebido à imagem e semelhança de Deus, significa que o ser humano não é Deus, é sua criatura, sua dignidade 
particular procede não de si mesmo, mas de seu Criador e, portanto, é partilhada com todos os outros seres humanos (SUPIOT, 2007, p. 7-11).

Para o Alain Supiot (2007, p. 15), é preciso inserir todos os seres humanos numa mesma identidade universal, tendo em vista que o ser humano ao mesmo tempo em que é único, por sua própria personalidade, é semelhante a todos os outros.

Ainda, supracitado autor explica que a noção de pessoa engloba o espírito e a matéria em sua unidade e não como dois universos radicalmente separados (SUPIOT, 2007, p. 27-29). Sendo este o diferencial entre as pessoas e as coisas. Portanto, a própria pessoa, seu corpo e as obras de espírito, não podem ser tratados como puros objetos à disposição do ser humano.

Portanto, para o efetivo respeito da dignidade da pessoa humana, é preciso que o indivíduo adquira a consciência de si e do outro, e assim, frear suas "pulsões destrutivas" (MOTTA, 2012, p. 233).

Por sua vez, Alessandro Severino Váler Zenni (2006, p. 73) apresenta um modelo de concepção humana e social marcadas pelo realismo aristotélico, amainado pelas moderações tomistas com a inserção de ideia de alma como caractere tipicamente humano.

Explica o referido autor que para o desenvolvimento e aperfeiçoamento do homem é indispensável o seu grupo social, afinal, toda pessoa, movendo-se rumo a um "telus"5 denunciado pela razão, recebe a convocação natural de valores e percebe-se parte de uma engrenagem totalizante, isto é, da própria sociedade (SUPIOT, 2007, p. 16).

Por consequência, o homem, sendo parte do todo, convive, tem participação e é afetado pelo agir do outro, existindo uma direção comum de suas ações ao bem de todos. O bem comum é o fim de todo grupo e, portanto, de todo homem. É preciso, portanto, harmonizar as liberdades dos integrantes dos grupos com o bem comum (SUPIOT, 2007, p. 17). Afinal, o ser humano vive e se relaciona em sociedade, precisa do outro para sua subsistência, por consequência, ao exercer sua liberdade, deve-se ter em mente o bem comum de seu próprio grupo, sob pena de sacrificar a sua própria existência, uma vez que prejudica o seu próprio grupo social.

Há uma proposta do supracitado autor de retorno à metafísica, pois os seres humanos, naturalmente associados, desde a pequena corporação familiar ao mais aperfeiçoado grupo, "gozam de uma mesma Causa Eficiente", o bem comum do próprio grupo. Se o ser humano destruir seu próprio grupo, agir de forma contrária ao bem comum, estará destruindo a si mesmo. "Os homens passam a ser causa e fim de si mesmos na promoção do Bem comum, enquanto vida for convívio" (ZENNI, 2006, p. 17). 
A partir destas concepções, verifica-se que o fundamental é a necessária reflexão do indivíduo para a sua própria natureza humana. Independente de concepções religiosas, o ser humano deve ter em mente de que a sua própria dignidade também está no outro, por que este é seu semelhante, e todos pertencem a mesma espécie homo sapiens. É preciso resgatar esta noção de dignidade e de respeito mútuo, pois só assim será possível evidenciar, de fato, o dever de cuidado e a preocupação com o outro na sociedade, como também nas relações familiares.

Somente com estes aspectos, o afeto traduzido em cuidado, se consolidará como princípio norte das famílias, e a dignidade da pessoa humana de cada membro familiar, especialmente das crianças e dos adolescentes, será devidamente respeitada e concretizada.

Afinal, a família é a entidade social responsável pelo desenvolvimento e formação de novos cidadãos que atuarão na sociedade no futuro.

Neste sentido Clayton Reis preceitua:

O lar é assim, a oficina da construção da personalidade da criança, o atelier em que os pais pintam na tela branca as variadas cores e figuras da existência humana. O sucesso na modelagem da personalidade da criança está relacionado com a sensibilidade e a responsabilidade dos progenitores, sempre voltados para a obtenção dos resultados almejados (REIS, PINTO, 2012, p. 508).

Torna-se essencial, portanto, para o homem retornar à metafísica, ao sentido de sua existência, de auto-realização, voltando-se ao bem comum, ao reconhecimento de si próprio no outro, a fim de romper com a cultura da irresponsabilidade na seara familiar e assumir os seus deveres perante as crianças e os adolescentes, bem como à importância do pleno desenvolvimento de personalidade destes para a formação de novos cidadãos íntegros.

Ao contrário da promessa capitalista, o consumo não é sinônimo de felicidade ou de auto-realização humana (BAUMAN, 2008, p. 63), muito menos de compromisso com o próximo. O fim do ser humano é mais do que um simples ato de consumir, sua essência ultrapassa os limites da racionalidade e da ciência, que depende, por sua vez, da concepção do respeito e da dignidade do outro. O homem tem em sua essência o relacionamento com o outro. A sua finalidade é, portanto, o convívio harmônico e não o consumo.

\footnotetext{
${ }^{5}$ Finalidade natural.
} 


\section{CONCLUSÃO}

A cultura consumerista imposta pelo modelo econômico capitalista e liberal transformou o homem num ser apático, vazio e nihilista, desapegado a uma identidade universal, exaltando valores de um ser individualista, que vivencia a era do hipermaterialismo ao invés de cultuar valores de espírito.

A ideia de Estado liberal, neutro frente as liberdades individuais, fez do ser humano um ser totalmente egoísta, preocupado apenas em exteriorizar a sua liberdade sem o comprometimento e cuidado com o outro.

A sociedade de consumo estabelece um verdadeiro fetichismo no ato de adquirir uma mercadoria, onde esta tem a finalidade de trazer felicidade e satisfazer uma necessidade pessoal do seu adquirente comprador, que é posto como sujeito soberano, autônomo, individual, racional e autossuficiente.

Neste cenário, Alessandro Severino Vallér Zenni apresenta cinco causas da crise social e jurídica vivenciada pela modernidade: a liberdade individualista ética e política ou moralismo subjetivista; o antropocentrismo humanista; o individualismo econômico ou capitalismo liberal: o individualismo político ou contratualismo; e o atomismo massificante.

Os efeitos destas causas são seres completamente massificados, sem essência universal, mergulhados numa profunda depressão por desconhecerem a realidade de sua estrutura ontológica e axiológica. Por não encontrarem limites aos desejos, perderam a completa noção de responsabilidade, acreditam serem detentores de direitos absolutos, sem a respectiva noção dos deveres.

E todo este cenário da modernidade repercute também consequências nas relações familiares. Hodiernamente, não são poucos os casos em que as famílias são formadas sem o comprometimento com o outro e sem o cuidado. Relações que se constroem com a valorização dos aspectos materiais e da riqueza ao invés de valores do espírito; relacionamentos rompidos, justamente pela falta de afetividade e de dever de cuidado para com o outro, que utilizam dos filhos para atingir o ex-cônjuge, com a prática de alienação parental; e também a possibilidade do casal praticar eugenia na formação do embrião em decorrência da utilização de técnicas de reprodução humana assistida na realização do projeto parental.

Situações em que os filhos são tidos como meios para interesses e até mesmo para vingança alheia. Há nitidamente falta de identidade universal que faz com que o homem desrespeite os interesses e os direitos de personalidade do próximo, principalmente das crianças e dos adolescentes, os seres mais vulneráveis e desprotegidos destas relações irresponsáveis, as 
quais as pessoas não compreendem o verdadeiro sentido da afetividade, da dignidade da pessoa humana e da parentalidade responsável.

É fato que o poder judiciário impõe indenizações para a prática de atos ilícitos que lesem os direitos de personalidade da criança e do adolescente, como também punições como a prisão no caso do devedor de pensão alimentícia, contudo, são decisões que por si só não solucionam os problemas.

Dessa forma, é preciso que o homem retome o verdadeiro sentido de sua existência, que não se restringe ao mero poder aquisitivo, mas sim à metafísica, a sua auto-realização. $\mathrm{O}$ ser humano deve voltar-se a uma identidade universal, e buscar a realização do bem comum, tendo em vista que a sua finalidade é o convívio em sociedade, e praticando o mal ao grupo, consequentemente pratica o mal para si, tendo em vista que é parte absolutamente necessária do todo.

É essencial que o homem reconhecendo a existência de si próprio, passe, assim, ter a consciência do outro, a fim de romper com a cultura da irresponsabilidade que permeia as relações familiares, e assumir os seus deveres perante as crianças e os adolescentes, com o pleno desenvolvimento da personalidade destes para a formação de novos cidadãos íntegros.

Por sua vez, caberia ao direito voltar-se à auto-realização humana, e procurar soluções razoáveis através do ideal de justiça, e não somente na racionalidade objetiva imposta pelo positivismo jurídico. É preciso o resgate da identidade universal do ser humano, que não se encontra exteriorizada nos bens materiais, e sim em sua própria natureza, para que cada ser se identifique com o seu próximo, e passe a promulgar valores de respeito mútuo e de dignidade.

\section{REFERÊNCIAS}

AGUIAR, Mônica. Direito à Filiação e Bioética. Rio de Janeiro: Forense, 2005.

BAUMAN, Zygmunt. Vida para Consumo: a transformação das pessoas em mercadoria.

Trad. Carlos Alberto Medeiros. Rio de Janeiro: Zahar, 2008.

BRASIL, Constituição Federal de 1988.

Disponível em: <http://www.planalto.gov.br/ccivil_03/constituicao/constituicao.htm> Acesso: 12 mar. 2013.

\section{Lei 5.869, Código de Processo Civil.}

Disponível em: < http://www.planalto.gov.br/ccivil_03/Leis/L5869.htm> Acesso: 06 set. 2013.

Resolução 2.013/2013 do Conselho Federal de Medicina. Disponível em: http://portal.cfm.org.br/images PDF/resoluocfm\%202013.2013.pdf. Acesso em: 06 set. 2013.

CARDIN, Valéria Silva Galdino. Dano Moral no Direito de Família. São Paulo: Saraiva, 2012. 
Do planejamento familiar e da paternidade responsável na reprodução assistida. In: XVIII Congresso Nacional do Conpedi, 2009, São Paulo. Estado, globalização e soberania: o Direito do século XXI. Florianópolis : Fundação Boiteux, 2009.

ROSA, Letícia Carla Baptista. Do Status jurídico do Embrião Crioconservado e do Princípio da Dignidade da Pessoa Humana frente a Utilização das Técnicas de Reprodução Humana Assistida. XXI Congresso Nacional do Conpedi. Niterói/RJ, 2012.

CARLIN, Volnei Ivo. Ética e Bioética. Florianópolis: Terceiro Milênio, 1998. DIAS, Maria Berenice. Manual de Direito das Famílias. 4 ed. São Paulo: Revista dos Tribunais, 2007.

FACHIN, Luiz Edson. Discriminação por Motivos Genéticos. In: FREIRE DE SÁ, Maria de Fátima; NAVES, Bruno Torquato de Oliveira. Bioética, Biodireito e o novo Código Civil de 2002. Belo Horizonte: Del Rey, 2004.

FÉO, Cristina de Oliveira. A Seleção de Embriões e Problemas Éticos. In: GUERRA, Arthur Magno e Silva (coord.). Biodireito e Bioética: uma introdução crítica. Rio de Janeiro: América Jurídica, 2005.

GIRARDI, Viviane. Famílias Contemporâneas, filiação e Afeto: a possibilidade jurídica da adoção por homossexuais. Porto Alegre: Livraria do Advogado, 2005.

HABERMAS, Jürgen. O futuro da natureza humana. São Paulo: Martins Fontes, 2004.

LAGRASTA NETO, Caetano; TARTUCE, Flávio; SIMÃO, José Fernando. Direito de Família: novas tendências e julgamentos emblemáticos. 2 ed. São Paulo: Atlas, 2012.

LIPOVETSKY, Gilles. A Felicidade Paradoxal: ensaio sobre a sociedade de hiperconsumo. (Tradução: Maria Lucia Machado). São Paulo: Companhia das Letras, 2007.

MADALENO, Rolf. Curso de Direito de Família. 4 ed. Rio de Janeiro: Forense, 2011.

MADALENO, Rolf. Repensando o Direito de Família. Porto Alegre: Livraria do Advogado, 2007.

MARX, Karl; ENGELS, Friedrich. A Ideologia Alemã: teses sobre Feuerbach. Tradução: Silvio Donizete Chagas. São Paulo: Centauro, 2005.

MORAES, Benjamin. Aspectos legais do planejamento familiar. In: Textos e Documentos, ano II, n. 11, nov. 1980.

MOTTA, Ivan Dias da. A Juridificação dos Direitos Humanos no Estado Democrático de Direito. In: CHITOLINA, Claudinei Luiz; PEREIRA, José Aparecido; OLIVEIRA, Lino Batista de; BORDIN, Reginaldo Aliçandro (orgs.). Estado, Indivíduo e Sociedade: problemas contemporâneos. [s.1.]: Paço Editorial, 2012.

REIS, Clayton; PINTO, Simone Xander. O Abandono Afetivo do Filho como Violação dos Direitos da Personalidade. Revista Jurídica Cesumar - Mestrado, v. 12, n. 2, p. 503-523, jul./dez. 2012. 
ROSA, Letícia Carla Baptista; CARDIN, Valéria Silva Galdino. Da realização do projeto homoparental por meio da utilização da reprodução humana assistida. XXI Encontro Nacional do CONPEDI, Uberlândia. 2012.

SUPIOT, Alain. Homo Juridicus: ensaio sobre a função antropológica do direito. Trad: Maria Ermantina de Almeida Prado Galvão. São Paulo: Martins Fontes, 2007.

SURROGATE ofered \$10,000 to abort baby. Disponível em:

<http://edition.cnn.com/2013/03/04/health/surrogacy-kelley-legal-battle> Acesso: 04 set.

2013.

ZENNI, Alessandro Severino Vallér. A Crise do Direito Liberal na Pós-modernidade. Porto Alegre: Sérgio Antonio Frabis, 2006. 